\title{
GERMINAÇÃO E MATURIDADE FISIOLÓGICA DE SEMENTES DE Piptadenia viridiflora (Kunth.) Benth RELACIONADAS A ESTÁDIOS DE FRUTIFICAÇÃO E CONSERVAÇÃO PÓS-COLHEITA ${ }^{1}$
}

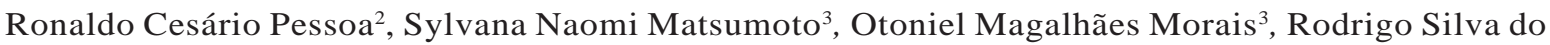 \\ Vale $^{4}$ e Jessé Moreira Lima ${ }^{5}$
}

\begin{abstract}
RESUMO - O objetivo deste trabalho foi verificar o efeito dos estádios de frutificação e formas de conservação na germinação e qualidade fisiológica de sementes de surucucu. Em 25 árvores na região de Vitória da Conquista, BA, foram realizadas coletas de frutos no período de 17/05 a 9/07 de 2007, em intervalos de sete dias a partir do início da frutificação, caracterizando oito estádios de desenvolvimento das vagens. Cada período de coleta foi definido por lotes diferenciados de sementes, sendo realizadas avaliações de massas fresca e seca de 100 sementes e teor de água. As sementes de cada uma das oito coletas foram mantidas em condições ambientais de laboratório, sendo subdivididas em dois lotes: em um lote, as sementes permaneceram no interior das vagens e, no outro, as vagens foram eliminadas. Após o período de 49 dias a partir do início da frutificação, massas fresca e seca de 100 sementes e teor de água foram determinados. Posteriormente, as sementes foram submetidas a testes de germinação em câmara tipo BOD, com temperatura de $25^{\circ} \mathrm{C}$, em regime de fotoperíodo de $8 \mathrm{~h}$ de luz. Depois de cinco dias foi realizada a primeira contagem de germinação e aos 10 dias, avaliadas as seguintes características: porcentagem de germinação, plântulas anormais e classificação do vigor das plântulas (vigor alto, médio e baixo). A presença das vagens durante o período de conservação das sementes foi fator determinante para a qualidade fisiológica das sementes. A germinação e o acúmulo de matéria seca determinados por ocasião do teste de germinação aumentaram com o período de frutificação, atingindo o máximo aos 37 dias.
\end{abstract}

Palavras-chave: Vigor, Conservação e Surucucu.

\section{GERMINATION AND PHYSIOLOGICAL MATURITY IN SEEDS OF Piptadenia viridiflora (Kunth.) Benth RELATED TO FRUITING TIMES AND FORMS OF POST-HARVEST CONSERVATION}

\begin{abstract}
The objective of this study was to investigate the effect of different fruiting stages and conservation techniques on the germination and physiological quality of surucucu seeds. Fruits were collected on eight occasions from 25 trees in the region of Vitória da Conquista - BA, in the period from 05/17 to 07/09 2007, at sevenday intervals from the beginning of the fruiting stage. Each collection period was characterized by distinct seed lots. Evaluations were made for green and dry weight of 100 seeds and water content. The seeds in each of the eight collections were maintained under room conditions in the laboratory, and were subdivided into two lots: in the first, the seeds remained inside their pods, while in the other the pods were eliminated. After a 49-day period from the beginning of fruiting, determinations were made for green and dry weight of 100 seeds and water content. The seeds were then submitted to germination tests in a BOD incubator adjusted to $25^{\circ} \mathrm{C}$, with an 8:16 hr (light:dark) photoperiod. The first germination count was made after five days. At ten days, evaluations were made for germination percentage and abnormal seedlings, and plantlets were classified as to their vigor (high, medium, and low). Germination increased as the fruiting period progressed, and was directly related to dry matter accumulation in the seeds, as determined during the germination test.
\end{abstract}

Keywords: Vigor, Conservation and Surucucu.

\footnotetext{
${ }^{1}$ Recebido em 26.11.2007 e aceito para publicação em 02.03.2010.

${ }^{2}$ Superintendência de Políticas Florestais Conservação e Biodiversidade (SFC). E-mail: <ronaldopessoacra1@yahoo.com.br>.

${ }^{3}$ Universidade Estadual do Sudoeste da Bahia, UESB, Brasil. E-mail: <sylvananaomi@yahoo.com.br>.

${ }^{4}$ Universidade Federal Rural da Amazônia, UFRA, Brasil. E-mail: <rodrigo.vale@ufra.edu.br>.

${ }^{5}$ Programa de Pós-Graduação em Agronomia da Universidade Estadual do Sudoeste da Bahia, UESB, Brasil. E-mail: <jesseagro@yahoo.com.br>.
} 


\section{INTRODUÇÃO}

Estudos sobre a propagação das espécies nativas da caatinga, principalmente as leguminosas arbóreas, são escassos. Devido à sua elevada adaptação às condições bióticas e abióticas ocorrentes na região semiárida do Nordeste brasileiro, estas espécies representam cerca de $80 \%$ do bioma Caatinga.

A coleta de sementes e propagação dessas espécies são ações necessárias para viabilizar a renovação da vegetação, recuperar áreas degradadas, estabelecer bancos de germoplasma e programas de melhoramento e sistematizar plantios para exploração econômica de frutos, madeiras e produtos medicinais (FOWLER e MARTINS, 2001). Os conhecimentos específicos sobre o ponto de maturidade fisiológica, germinação, dormência e potencial de armazenamento das sementes são essenciais para concretizar as ações anteriormente citadas. A busca dessa informação tem sido meta constante entre os pesquisadores, e, nesse contexto, vários trabalhos vêm sendo conduzidos (PONTES et al., 2002; SOUZAe LIMA, 1985; MARTINS et al., 1992). De acordo com Alves et al. (2005), o estudo sobre a maturidade fisiológica das sementes é importante para o conhecimento da reprodução das espécies vegetais, possibilitando a previsão da época adequada de colheita.

Nakagawa et al. (2005) verificaram que, quando as sementes são armazenadas e secas no interior das vagens, há maior número de sementes imaturas e ocorrem a antecipação e elevação do número de sementes duras.

Piptadenia viridiflora (Kunth) Benth Mimosaceae, popularmente conhecida como surucucu, é uma planta rústica, pioneira, de crescimento rápido, com ampla adaptação a terrenos secos e bem drenados, ocorrendo em áreas do Nordeste do Brasil e nas formações chaquenhas do Pantanal do Mato Grosso (LORENZI, 2000). Apesar da agressividade de seus espinhos, essa é uma das espécies mais promissoras para a implantação de florestas de uso múltiplo, ou seja, para a produção de lenha e carvão, devido ao seu rápido crescimento e por possuir madeira de elevada densidade. A madeira da surucucu é utilizada como lenha no setor ceramista da região Sudoeste do Estado da Bahia e como carvão vegetal para atender ao parque siderúrgico de Minas Gerais.

A introdução dessa espécie tem sido indicada para trabalhos de recuperação de áreas degradadas e para segmentos ligados à matriz energética, como matéria-prima, devido à sua elevada adaptação a um regime de manejo caracterizado por diversos ciclos de corte. Assim, para a viabilidade de plantios dessa leguminosa torna-se importante a adequação de técnicas de manejo para a produção de mudas. Definição de padrões sobre aspectos morfológicos, fisiológicos e melhor época para colheita dos frutos são fundamentais e de grande auxílio para viveiristas e tecnologia de sementes.

O objetivo deste trabalho foi verificar o efeito dos estádios de frutificação e formas de conservação na germinação e qualidade fisiológica de sementes de surucucu.

\section{MATERIAL E MÉTODOS}

O experimento foi conduzido no período de maio a julho de 2007, no Município de Vitória da Conquista, região Sudoeste da Bahia, onde predomina o clima semiárido com temperatura média de $20,2^{\circ} \mathrm{C}$ (SILVA et al., 2007) e pluviosidade anual média de 762,8 mm, concentrada entre os meses de novembro e março (MURTA et al., 2005).

Foram marcadas 25 árvores-matrizes, sendo escolhidas as mais vigorosas e com boa aparência fitossanitária, com altura variando de 5 a $8 \mathrm{~m}$ e idade aproximada de 10 anos. O estádio de plena antese das flores ( $50 \%$ da copa com ramos em florescimento) ocorreu na primeira semana do mês de fevereiro de 2007. As coletas dos frutos foram iniciadas na segunda quinzena de maio, quando as vagens e sementes apresentavam coloração verde, sendo esse estádio considerado como início da frutificação. A cada sete dias, frutos foram colhidos manualmente, com o auxílio de tesoura de poda, tomando-se o cuidado para não provocar danos mecânicos nos frutos.

Imediatamente após a colheita, amostras de frutos foram acondicionadas em embalagens plásticas e encaminhadas ao Laboratório de Análise de Sementes da Universidade Estadual do Sudoeste da Bahia, Campus de Vitória da Conquista, para evitar que ocorressem alterações no teor de água. No Laboratório, a massa fresca e seca das sementes foi determinada a partir de pesagens em balança analítica com precisão de 0,0001 g. A massa seca das sementes foi obtida após a permanência em estufa a $105 \pm 3^{\circ} \mathrm{C}$ por $24 \mathrm{~h}$, em quatro repetições de 50 sementes cada. Após o período de secagem, as amostras foram mantidas sob vácuo em 
dessecador por 10 min e, quando o material atingiu temperatura ambiente, foram realizadas as pesagens. A partir dos dados de massas fresca e seca foi determinado o teor de água, sendo expresso em porcentagem em base úmida. Esse procedimento foi sistematicamente reproduzido em oito épocas de coleta previamente estabelecidas, a partir do início da frutificação, em intervalos de sete dias, durante um período de 49 dias. Durante esse período, a cada coleta as sementes permaneceram armazenadas no Laboratório de Tecnologia de Sementes, sendo conservadas dentro e fora das vagens.

Para avaliar a germinação, após o período de conservação foi instalado um experimento constituído a partir do delineamento inteiramente casualizado, em esquema fatorial com quatro repetições, sendo as parcelas constituídas por 50 sementes. A forma de conservação das sementes (dentro e fora das vagens) foi considerada como tratamento, bem como os oito diferentes estádios de frutificação delas.

No momento da instalação dos testes, o teor de água de todas as amostras foi mantido entre 12 e 13\%. Foram realizados testes de vigor (primeira contagem de germinação realizada aos cinco dias após o início do teste), de germinação (avaliação da protrusão da radícula aos 10 dias após o início da instalação do teste), porcentagem de plântulas normais e anormais, plântulas com alto, médio e baixo vigor de surucucu em diferentes estádios de frutificação e formas de conservação.
Os testes de germinação foram instalados acondicionando-se as sementes em papel germitest umedecido com água deionizada na proporção de 2,5 vezes o seu peso de matéria seca. Os rolos de papel germitest contendo as sementes foram colocados em sacos plásticos e postos em germinador, regulado à temperatura de $25{ }^{\circ} \mathrm{C}$ e fotoperíodo de oito horas de luz. As contagens foram realizadas no quinto e décimo dia após a semeadura, conforme descrito por BRASIL (1992). Os dados foram submetidos à análise de variância, por meio do programa SAEG 8.1 (RIBEIRO JÚNIOR, 2001). Quando o efeito do período de coleta foi considerado, para as sementes conservadas dentro e fora da vagem, os modelos foram ajustados, utilizando-se como referência a análise de variância da regressão, o significado biológico e o valor do coeficiente de correlação.

Os valores obtidos a partir do teste de germinação foram transformados em arcosen $\sqrt{ }(\mathrm{x} / 100)$ e quando com valor zero, em $\sqrt{ }(x+0,5)$.

\section{RESULTADOS}

Aos 10 dias após a instalação do teste de germinação foram observados os valores máximos (17\%). O vigor e a porcentagem de germinação foram superiores para as sementes conservadas dentro das vagens, sendo verificados índices de 0,26 (7\%) e 0,42 (17\%), respectivamente (Tabela 1). Quando o vigor das plântulas normais foi avaliado, foram observadas diferenças entre as formas de conservação (dentro e fora da vagem) para alto e médio vigor, com valores

Tabela 1 - Germinação de sementes aos 5 e 10 dias após início do teste, plântulas anormais, plântulas com alto, médio e baixo vigor de Piptadenia viridiflora em função da conservação com a presença e retirada de vagens depois da coleta, durante o período de 49 dias após o início da frutificação.

Table 1 - Germination of seeds at five and ten days after the beginning of the test, abnormal seedlings, seedlings with high, medium and low vigor of Piptadenia viridiflora related to post-harvest with presence and withdrawal string beans, during a period of 49 days after full fruiting.

\begin{tabular}{|c|c|c|c|c|c|c|c|c|c|c|c|c|}
\hline \multirow[b]{2}{*}{ C. vagem } & \multicolumn{2}{|c|}{$\begin{array}{c}\text { Germinação após } \\
\text { cinco dias (\%) }\end{array}$} & \multicolumn{2}{|c|}{$\begin{array}{c}\text { Germinação } \\
\text { após } 10 \text { dias(\%) }\end{array}$} & \multicolumn{2}{|c|}{$\begin{array}{c}\text { Plântulas } \\
\text { anormais(\%) }\end{array}$} & \multicolumn{2}{|c|}{$\begin{array}{l}\text { Plântulasalto } \\
\text { vigor(\%) }\end{array}$} & \multicolumn{2}{|c|}{$\begin{array}{c}\text { Plântulas } \\
\text { médio vigor (\%) }\end{array}$} & \multicolumn{2}{|c|}{$\begin{array}{c}\text { Plântulasbaixo } \\
\text { vigor (\%) }\end{array}$} \\
\hline & $\begin{array}{c}0,2640 \\
(6,81 \%)^{* *}\end{array}$ & $\mathrm{~A}^{*}$ & $\begin{array}{c}0,4242 \\
(16,94 \%)\end{array}$ & $\mathrm{A}$ & $\begin{array}{l}0,1666 \\
(2,75 \%)\end{array}$ & $\mathrm{A}$ & $\begin{array}{c}0,2395 \\
(5,63 \%)\end{array}$ & $\mathrm{A}$ & $\begin{array}{c}0,1899 \\
(3,56 \%)\end{array}$ & $\mathrm{A}$ & $\begin{array}{c}0,2255 \\
(5,00 \%)\end{array}$ & $\bar{A}$ \\
\hline S. vagem & $\begin{array}{c}0,1858 \\
(3,41 \%)\end{array}$ & B & $\begin{array}{c}0,3080 \\
(9,19 \%)\end{array}$ & B & $\begin{array}{c}0,1278 \\
(1,63 \%)\end{array}$ & A & $\begin{array}{c}0,1722 \\
(2,94 \%)\end{array}$ & B & $\begin{array}{c}0,1327 \\
(1,75 \%)\end{array}$ & B & $\begin{array}{c}0,1704 \\
(2,88 \%)\end{array}$ & A \\
\hline
\end{tabular}

*Médias seguidas pela mesma letra na coluna não diferem entre si, pela análise de variância, a 5\% de probabilidade.

** Valores originais correspondentes aos dados transformados em arcosen $\sqrt{ }(x / 100$, utilizados na análise de variância.

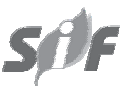

Revista Árvore, Viçosa-MG, v.34, n.4, p.617-625, 2010 
superiores para as plântulas provenientes de sementes conservadas dentro das vagens $(5,63 \%$ e $3,56 \%$, respectivamente) (Tabela 1 ). Não foi verificada diferença entre plântulas anormais, quando as sementes foram armazenadas dentro e fora das vagens, obtendo-se valores médios de 0,17 (2\%).

Os dados referentes ao acúmulo de massas fresca e seca das sementes no momento da colheita (Figura 1) se ajustaram aos modelos quadrático e cúbico, respectivamente. Foi observada uma relação decrescente direta para massa fresca, em que o maior valor (11,77 g) foi verificado aos 10 dias, e a partir dessa data ocorreu relação decrescente entre a massa fresca das sementes e o período de coleta até os 49 dias após o início da frutificação. O maior valor de massa seca (5,0409 g) foi observado aos 18 dias após a plena frutificação, porém esse valor diferiu do ponto de maturidade, uma vez que as sementes, nesse ponto, apresentavam alto teor de água, apresentando baixa germinação pela imaturidade delas nesse período.

Quando foi constatado o acúmulo máximo de massa seca, o teor de água das sementes se manteve elevado, e a porcentagem de germinação diminuiu substancialmente, não coincidindo com valores máximos de germinação, pois as sementes se encontravam ainda

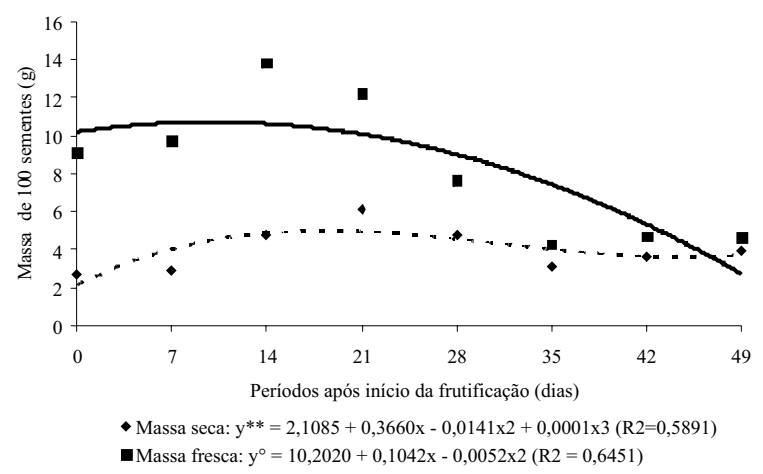

**, ${ }^{0}$ Significativo a 1 e $10 \%$ de probabilidade, pela análise de variância da regressão.

Figura 1-Massas fresca e seca de sementes de surucucu (Piptadenia viridiflora) no momento da coleta, em função de diferentes estádios de frutificação. Vitória da Conquista, Bahia, 2007.

Figure 1 - Fresh and dry mass of surucucu seeds (Piptadenia viridiflora) at harvesting time, related to different fruiting stages and post-harvest conservation with presence and withdrawal string beans. Vitória da Conquista, Bahia, Brazil, 2007. imaturas. Portanto, para os valores de massa seca avaliados no momento da coleta das sementes, foi conceituado o momento de maior acúmulo de massa seca como "ponto de maturidade de massa”, devido à ausência de sincronia entre essa variável e a capacidade germinativa da semente.

Por ocasião do teste de germinação, comportamento semelhante foi verificado para massas fresca e seca avaliadas em função dos períodos de coleta, no decorrer de 49 dias após o início da frutificação. Analisando a Figura 2, observou-se o ajuste de modelo polinomial de quarto grau para as massas fresca e seca das sementes conservadas dentro das vagens em relação aos dias após o início da frutificação. O máximo acúmulo de massa fresca ocorreu aos 44 dias após o início da frutificação, sendo observado o valor de 5,6047 g.

Para a relação entre massa seca das sementes conservadas fora das vagens e períodos de coleta após o início da frutificação, obtidos no momento do teste de germinação, não foi possível o ajuste de modelo

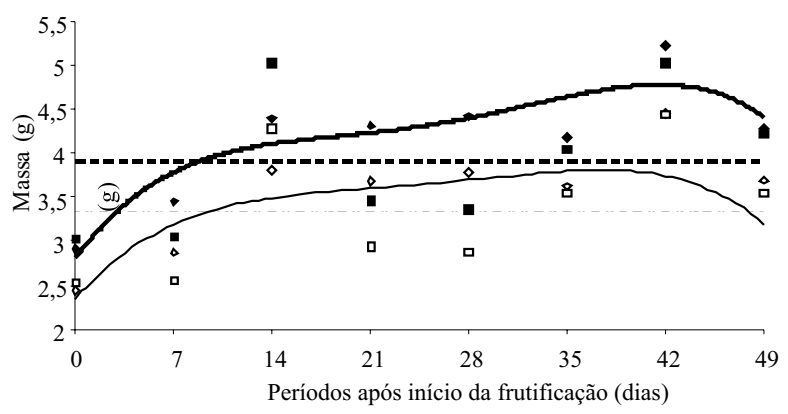

- Massa fresca de sementes com vagem: $\mathrm{y}^{* *}=2,8079+0,2151 \mathrm{x}-0,0133 \mathrm{x}^{2}+0,0004 \mathrm{x}^{3}-0,000004 \mathrm{x}^{4}\left(\mathrm{R}^{2}=0,809\right)$

- Massa fresca de sementes sem vagem: $y=3,8943$

- Massa seca de sementes com vagem: $\mathrm{y}^{* *}=2,3417+0,1841 \mathrm{x}-0,0109 \mathrm{x}^{2}+0,0003 \mathrm{x}^{3}-0,000003 \mathrm{x}^{4}\left(\mathrm{R}^{2}=0,8205\right)$

- Massa seca de sementes sem vagem: $y=3,3333$

**Significativo a 1\% de probabilidade, pela análise de variância da regressão.

Figura 2 - Massa fresca e massa seca de sementes de surucucu (Piptadenia viridiflora) em função de diferentes estádios de frutificação e formas de conservação após a coleta, determinadas por ocasião do teste de germinação. Vitória da Conquista, Bahia, 2007.

Figure 2 - Fresh and dry mass of surucucu seeds (Piptadenia viridiflora) related to different fruiting stages and post-harvest conservation, at the time of the germination test. Vitória da Conquista, Bahia, Brazil, 2007. 
(Figura 2). Foi ajustado o modelo polinomial de quarto grau, com valores máximos de acúmulo de massa seca aos 37 dias após o início da frutificação, quando foi observado o valor de 3,8047 g nas sementes conservadas dentro das vagens. Observou-se um acúmulo lento de massa seca nos períodos iniciais de formação das sementes, ocorrendo, em seguida, um aumento na velocidade até atingir o acúmulo máximo. A partir desse ponto, houve redução devido às perdas por respiração.

De acordo com os resultados apresentados na Figura 3, verificou-se que a relação entre a porcentagem de germinação a os períodos após o início da frutificação foi delineada pelo modelo cúbico. A maior porcentagem de germinação (18\%) foi obtida aos 37 dias após o início da frutificação e a menor (11\%), aos três dias após tal estádio.

Analisando os dados de massa seca (Figura 2) e germinação (Figura 3), verificou-se, por meio da derivação dos modelos, a ocorrência de valores máximos para ambos aos 37 dias e aos 38 dias para massa seca após o início da frutificação (Figura 2), o que comprova que a máxima capacidade de germinação coincide com o ponto máximo de acúmulo de massa. Foi verificada

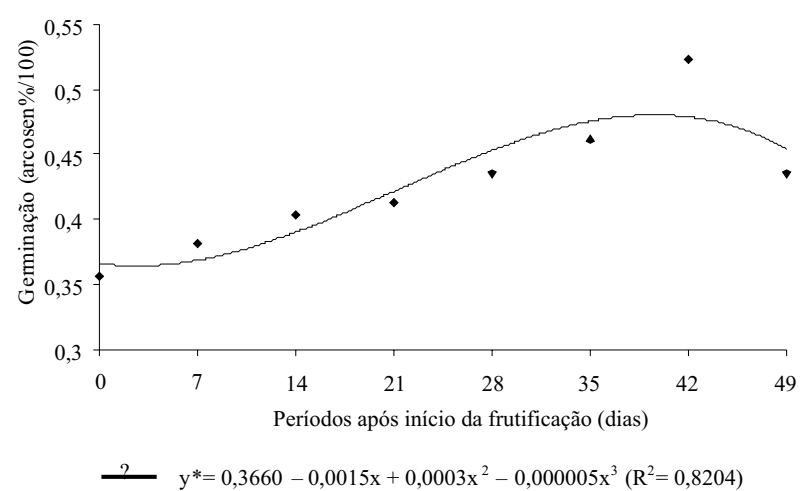

*Significativo a 5\% de probabilidade, pela análise de variância da regressão.

Figura 3 - Germinação de sementes de surucucu (Piptadenia viridiflora) em função de diferentes estádios de frutificação e presença e ausência da vagem após a coleta. Vitória da Conquista, Bahia, 2007.

Figure 3-Germination of surucucu seeds (Piptadenia viridiflora) related to different times after full fruiting stages and post-harvest conservation with a presence and absence of the string bean. Vitória da Conquista, Bahia, Brazil, 2007. correlação positiva entre massa seca e germinação aos 10 dias após o início do teste $(0,2815$, a $1 \%$ de probabilidade pelo teste de correlação de Pearson).

Quando a relação entre o teor de água avaliado no momento da coleta em função dos períodos foi avaliada, foi delineado o modelo cúbico (Figura 4A), ocorrendo comportamento decrescente e direto em relação aos períodos de frutificação. Neste trabalho, o teor de água das sementes permaneceu estável nas duas primeiras coletas, decrescendo a partir daí até
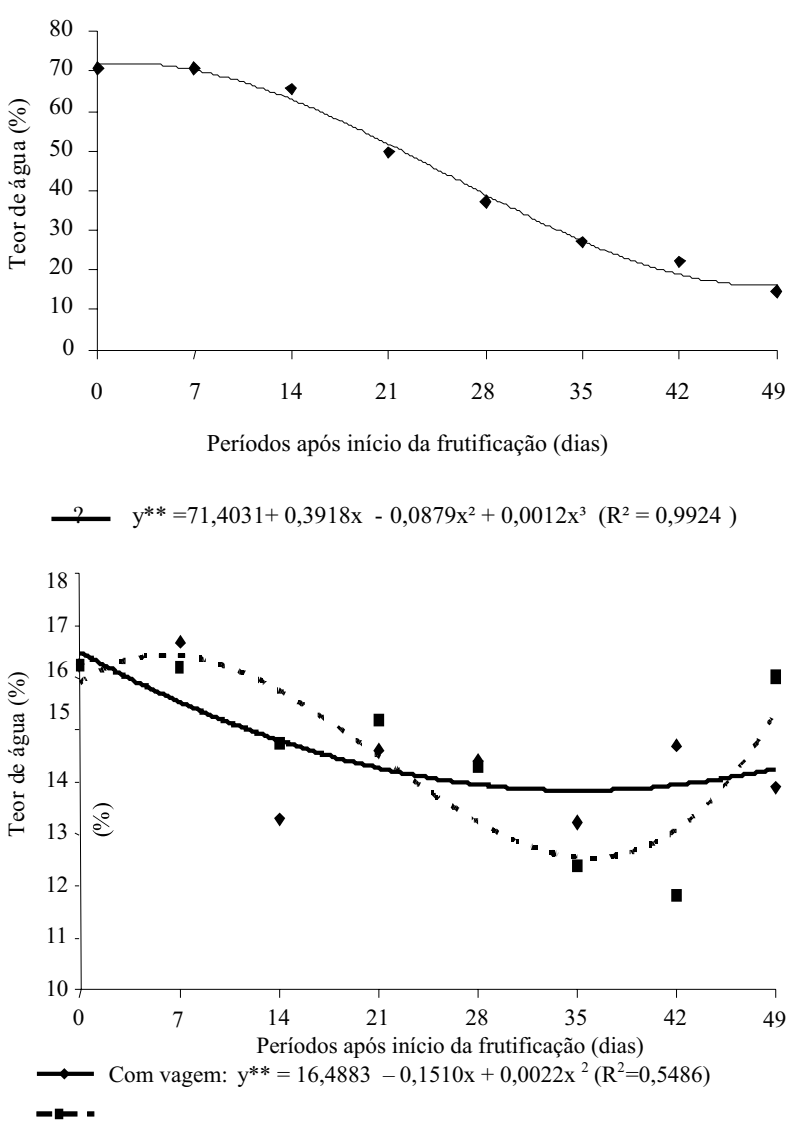

**Significativo a 1\% de probabilidade, pela análise de variância da regressão.

Figura 4-Teor de água das sementes de surucucu (Piptadenia viridiflora) no momento da coleta dos frutos (A) e por ocasião do teste de germinação (B), em função de diferentes estádios de frutificação. Vitória da Conquista, Bahia, 2007.

Figure 4- Water content of surucucu seeds (Piptadenia viridiflora) at the fruit harvesting (a) and at the germination test time (B), related to different fruiting stages and post-harvest conservation with and without string beans. Vitória da Conquista, Bahia, Brazil, 2007.

Revista Árvore, Viçosa-MG, v.34, n.4, p.617-625, 2010 
atingir a sétima coleta; a partir desse ponto, houve tendência à estabilidade de valores. Foi verificada uma elevada variação de valores (valor máximo de 70,40\% e mínimo de 20,73\%) durante o período de 49 dias após o início da frutificação.

De acordo com os resultados apresentados na Figura 4B, verificou-se que a relação entre o teor de água no momento do teste de germinação e os dias após o início da frutificação se ajustou ao modelo quadrático, para as sementes conservadas dentro das vagens. Quando as sementes foram conservadas dentro das vagens se observou redução no teor de água de 16,49\%, verificada no início da frutificação para um teor mínimo de 13,99\% no período de 33 dias após o início da frutificação. Embora tenha sido observada redução da umidade quanto mais precoce foi a retirada da vagem da planta-mãe, maiores foram os valores de teor de água das sementes. A estabilização do metabolismo fisiológico destas nesse período resultou na maior contribuição de compostos orgânicos para a redução do potencial hídrico, dificultando a perda de água pela semente para o ambiente.

Para as sementes conservadas sem a vagem, foi ajustado o modelo polinomial cúbico para a relação do teor de água das sementes em função dos períodos após o início da frutificação (Figura 4B). Embora os modelos definidos para o teor de água das sementes conservadas com e sem vagem tenham sido diferentes, foi observado comportamento semelhante, sendo verificada maior variação entre os valores do modelo ajustado para sementes conservadas sem a presença da vagem em relação ao lote mantido com vagem $(3,43$ e $2,5 \%$, respectivamente). O valor máximo de $16,66 \%$ foi verificado aos 65 dias após o início da frutificação, e o mínimo ocorreu aos 34 dias, com valor de 13,01\%.

Apesar da maior amplitude de variação de valores e da evidente correlação negativa entre o teor de água da semente avaliada no momento da coleta (Figura 4A) e a capacidade germinativa das sementes (Figura 3) (-0, 8291, significativa a $1 \%$, pelo teste de correlação de Pearson), efeito marcante dessa relação foi observado quando o teor de água foi determinado por ocasião do teste de germinação (Figura 4B). A avaliação do teor de água após os diferentes períodos de conservação resultou em diferencial de umidade menos expressivo. Entretanto, a queda nos índices de germinação das sementes mantidas sob conservação durante nove dias coincide com a elevação dos valores de umidade nesse mesmo período.

Revista Árvore, Viçosa-MG, v.34, n.4, p.617-625, 2010

\section{DISCUSSÃO}

A baixa magnitude da germinação foi relacionada à elevada incidência de sementes com impermeabilidade de tegumento (Tabela 1). Índices de 63\% a 33\% de sementes duras (dados não ilustrados) foram verificados nos diversos lotes avaliados neste estudo, quando armazenados com e sem as vagens. Esse tipo de dormência foi anteriormente observado em outras espécies da família Mimosaceae e Caesalpinaceae, como a acácia-negra (ROVERSI et al., 2002), a quaresmeira (LOPES et al., 2005), o sabiá (PASSOS et al., 2006), a canafístula (MELO e RODOLFO JÚNIOR, 2006) e a pata-de-vaca (MARTINELLI-SENEME et al., 2006). De acordo com Nakagawa et al. (2005), a dormência das sementes é uma estratégia das plantas que se instala durante a maturação, evitando a ocorrência da viviparidade e da germinação em época desfavorável. Quando a maturação das sementes é avaliada, tal fenômeno dificulta a definição do momento em que as sementes atingem a maturidade fisiológica. Entretanto, em estudos realizados por Lopes et al. (2005) e Nakagawa et al. (2005), embora a ocorrência da impermeabilidade do tegumento tenha afetado a magnitude da germinação, a definição da maturidade fisiológica foi possível quando parâmetros como teor de umidade e acúmulo de massa foram relacionados à germinação.

Foi verificado que a ocorrência dos valores máximos de massas seca e fresca no momento da coleta não coincidiu com a maior capacidade germinativa das sementes (Figura 1). Divergindo do resultado encontrado, Souza e Lima (1985), estudando o processo de maturação de sementes de Anadenanthera macrocarpa (Benth.) Brenan, observaram que a massa fresca e o índice de velocidade de germinação (IVG) foram os índices que melhor caracterizaram a maturidade fisiológica das sementes.

O incremento na germinação resultante da conservação das sementes no interior das vagens verificado neste estudo (Figura 1) foi anteriormente descrito para sementes de mucuna-preta, em trabalho realizado por Nakagawa et al. (2005). Em muitos estudos sobre a germinação de sementes provenientes de frutos carnosos foi demonstrada a relação positiva entre períodos de armazenamento de frutos destacados da planta-mãe e potencial de germinação de sementes. De acordo com Costa et al. (2006), o ponto de maturidade fisiológica pode ser influenciado por um período de 
repouso pós-colheita dos frutos, antes da extração das sementes. Para esses casos, desde que ocorra armazenamento conveniente, as sementes provenientes de frutos imaturos podem apresentar qualidade fisiológica comparável com aquelas de frutos maduros (BARBEDO et al., 1994). Tal comportamento é constantemente relacionado ao fluxo de material de reserva do fruto para as sementes, resultando em elevação de massa das sementes durante o período de conservação póscolheita. Para este estudo, além desses importantes processos de transporte, o elevado teor de água (Figura 3A) determinado na data de colheita e a duração dos períodos de conservação das vagens mantidas em laboratório resultaram em redução de massa das sementes. Essa redução foi sensivelmente mais intensa nas sementes que permaneceram em condição de laboratório, mantidas em vagens destacadas da planta-mãe, durante maior período de tempo. Sob tais condições, processos de conversão e catabolismo (respiração) de compostos constituintes da semente foram determinantes para a redução de massa das sementes. Tal fato pode ser observado pela comparação entre as massas no momento da coleta dos frutos e no momento do teste de germinação (Figuras 1 e 2). Entretanto, o diferencial de comportamento entre esses dois momentos (período de coleta e momento do teste) parece estar relacionado a um processo de maior complexidade. Nesse foco, o fluxo de hormônios vegetais entre sementes e frutos quando estes permanecem vinculados à planta-mãe também deve ser considerado. Para o estudo em análise, a alteração de hormônios inibidores como o ácido abscísico e giberelinas e auxinas é outro evento a ser considerado na germinação das sementes. Fatores relacionados à redistribuição de compostos entre casca, embrião e material de reserva devem ser ponderar, pois, principalmente para as Mimosáceas, a casca compõe grande parte da massa das sementes. Entretanto, essa se constitui em componente restritivo à germinação, pois a espessura e impermeabilidade do tegumento podem induzir ocorrência de sementes duras.

O efeito da forma de armazenamento das sementes (com e sem vagens) não foi verificado na ocorrência de plântulas anormais. Entretanto, Nakagawa et al. (2005), em estudos realizados sobre sementes de mucuna-preta, descreveram que a secagem no interior das vagens induz a um maior aporte de reservas, resultando em elevação da frequência de germinação de sementes imaturas. Fatores relacionados a características intrínsecas à espécie foram relacionados a tal divergência de comportamento entre este estudo e o trabalho citado anteriormente.

A relação entre a massa seca determinada no momento do teste e os períodos de frutificação (Figura 2) foi descrita por Carvalho e Nakagawa (2000), os quais definiram que o acúmulo de massa seca em uma semente em formação ocorre, inicialmente, de maneira lenta, em seguida começa a fase de rápido e constante acúmulo, até que o máximo é atingido. Esse acúmulo máximo é mantido por algum tempo, podendo, no final, sofrer pequeno decréscimo, como resultado das perdas por respiração.

A utilização do acúmulo de massa seca como índice de maturação também foi eficaz para a determinação do ponto de maturidade fisiológica de sementes de Pterogyne nitens Tul. (CARVALHO e outros, 1980) e de Myroxylon balsamum (L.) Harms (AGUIAR e BARCIELA, 1986). Resultados semelhantes foram obtidos para sementes de Tabebuia avellanedae Lorentz ex Griseb. (BARBOSA et al., 1992a), Torresia acreana Ducke (FIRMINO e outros, 1996) e de Cedrela fissilis Vell. (CORVELLO et al., 1999). No entanto, Barbosa e outros (1992b), ao estudarem a maturação de Copaifera langsdorffii Desf., observaram que o acúmulo de massa seca das sementes não foi considerado indicador adequado para a maturidade fisiológica, pois se manteve constante para as coletas de sementes realizadas em diferentes estádios de desenvolvimento do fruto.

O conteúdo de massa fresca de frutos e sementes, juntamente com a coloração dos frutos e a capacidade germinativa das sementes de Inga uruguensis Hook et Arn, foi considerado o melhore parâmetros para determinação do momento ideal de colheita (FIGLIOLIA e KAGEYAMA, 1994).

O comportamento massa seca das sementes conservadas dentro das vagens (Figura 2), verificado no momento do teste de germinação, foi semelhante ao obtido por Alves (2003) em estudo sobre a maturidade fisiológica de sementes de Mimosa caesalpiniifolia (Benth.). Neste estudo, o período de maior acúmulo de massa seca, quando determinada no momento do teste de germinação, coincidiu com a maior potencialidade de germinação. Tal correlação positiva entre os valores da massa seca e a porcentagem de germinação das sementes foi verificada também por Aguiar e Barciela (1986), os quais observaram que a capacidade máxima

Revista Árvore, Viçosa-MG, v.34, n.4, p.617-625, 2010 
de germinação de sementes de cabreúva, ou cabriúva, foi diretamente relacionada com o máximo acúmulo de matéria seca nas sementes.

O comportamento entre o teor de água das sementes avaliados no momento da coleta e os períodos de coleta (Figura 4A) foi semelhante aos obtidos por Regagnin et al. (1994). Esses autores definiram o índice de 62\% de teor de água como valor correspondente à ocorrência da maturidade fisiológica de sementes de Podocarpus lambertii Klotzsch. Carvalho et al. (1980) também utilizaram o teor de água das sementes de Pterogyne nitens Tul. como critério para auxiliar na determinação da maturidade fisiológica, recomendando a colheita das sementes com teor de água entre 60 e 65\%. Em sementes de Anadenanthera macrocarpa (Benth.) Brenan, o teor de água se manteve em torno de 57,9\% por ocasião do ponto de maturidade fisiológica (SOUZA e LIMA, 1985).

Martins e Silva (1997), avaliando a maturação de sementes em diferentes épocas de colheitas de Dalbergia nigra, verificaram que o grau de umidade das sementes decresceu continuamente ao longo do período estudado. O elevado grau de umidade inicial, verificado nas sementes das primeiras colheitas, e o seu posterior decréscimo foram relacionados à importância da água nos processos de enchimento e maturação das sementes. Para que os produtos fotossintetizados nas folhas sejam transportados para a semente em formação, sendo utilizados como material de construção e posteriormente como de reserva, é necessário que ela mantenha elevado grau de umidade, o que ocorre até o peso da matéria seca atingir seu valor máximo, quando, então, se inicia rápida desidratação (CARVALHO e NAKAGAWA, 2000).

A variação nos valores dos teores de água durante o processo de maturação, definidos no momento do teste de germinação, foi comentada por Carvalho e Nakagawa (2000) como fato natural decorrente do equilíbrio entre umidade do ar e da semente, sendo anteriormente observado para inúmeras sementes de espécies florestais nativas, a exemplo de Enterolobium contorsiliquum (Vell.) Morong (BORGES et al., 1980), Copaifera langsdorffii Desf (BARBOSA et al., 1992b) e Dalbergia nigra (Vell.) Fr. All ex Benth. (MARTINS e SILVA, 1997). Neste estudo foi verificado que a presença da vagem foi importante fator na redução das variações que definiram tal equilíbrio entre as sementes e a atmosfera circundante (Figura 4B).

\section{CONCLUSÃO}

A manutenção das vagens em procedimentos de conservação foi fator favorável à qualidade fisiológica das sementes de surucucu (vigor e germinação) nas condições do estudo.

O teor de água aliado ao máximo acúmulo de massa seca, avaliado por ocasião do teste de germinação, foi determinante para a definição da capacidade germinativa das sementes de surucucu.

Houve elevação da massa seca determinada por ocasião do teste e dos valores de germinação com o decorrer dos períodos de frutificação, atingindo o máximo aos 37 dias após o início da plena frutificação.

\section{AGRADECIMENTOS}

Ao Programa de Pós-Graduação em Agronomia da Universidade Estadual do Sudoeste da Bahia, pela oportunidade de ampliação de conhecimentos; e à Fundação Víctor Dequech, pela concessão da bolsa de pesquisa.

\section{REFERÊNCIAS}

AGUIAR, I. B.; BARCIELA, F. J. P. Maturação de sementes de cabreúva. Revista Brasileira de Sementes, v.8, n.3, p.63-71, 1986.

ALVES, E. U. et al. Maturação fisiológica de sementes de sabiá (Mimosa caesalpiniifolia Benth.). Revista Brasileira de Sementes, v.27, n.1, p.1-8, 2005.

BARBEDO, C. J. et al. Influência da idade e do período de repouso pós-colheita de frutos de pepino cv. Rubi na qualidade fisiológica de sementes. Horticultura Brasileira ., v.12, n.2, p.118-124, 1994.

BARBOSA, J. M.; AGUIAR, I. B.; SANTOS, S. R. G. Maturação de sementes de Copaifera langsdorffii Desf. Revista do Instituto Florestal, v.4, p.665-674, 1992.

BORGES, E. E. L.; BORGES, R. C. G.; TELES, F. F. F. Avaliação da maturação e dormência de sementes de orelha de negro. Revista Brasileira de Sementes, v.2, n.2, p.29-32, 1980.

BRASIL. Ministério da Agricultura e da Reforma Agrária. Regras para análise de sementes. Brasília: SNDA/DNDV/CLAV, 1992. 365p. 
CARVALHO, N. M.; NAKAGAWA, J. Sementes: ciência, tecnologia e produção. 4.ed. Campinas: FUNEP, 2000. 588p.

COSTA, C. J.; CARMONA, R.; NASCIMENTO, W. M. Idade e tempo de armazenamento de frutos e qualidade fisiológica de sementes de abóbora. Revista Brasileira de Sementes, v. 28, n.1, p.127-132, 2006.

FOWLER, J. A. P.; MARTINS, E G. Coleta de sementes. In: Manejo de sementes de espécies florestais. Colombo: EMBRAPA Florestas, 2001. p.9-13. (Documentos, 58).

LORENZI, H. Árvores brasileiras: manual de identificação e cultivo de plantas arbóreas nativas do Brasil. 3.ed. Nova Odessa: Instituto Plantarum, 2000. v.1. 351p.

MARTINELLI-SENEME, A. et al . Germinação e sanidade de sementes de Bauhinia. Revista Árvore, v.30, n.5, p.709-724, 2006.

MARTINS, C. C.; CARVALHO, N. M.; OLIVEIRA, A. P. Quebra de dormência de sementes de sabiá (Mimosa caesalpiniaefolia Benth.) Revista Brasileira de Sementes, v.14, n.1, p.5-8, 2001.

MARTINS, S. V.; SILVA, D. D. Maturação e época de colheita de sementes de Dalbergia nigra (Vell.) Fr. All. ex Benth. Revista Brasileira de Sementes, v.19, n.1, p.96-99, 1997.

MELO, R. R.; RODOLFO JÚNIOR, F. Superação de dormência em sementes e desenvolvimento inicial de canafístula (Cassia grandis L.f.). Revista Cientifica de Engenharia Florestal, v. 7, n.4, PAGINAS, 2006.
MURTA, R. M. et al. Precipitação pluvial mensal em níveis de probabilidade pela distribuição gama para duas localidades do Sudoeste da Bahia. Ciência Agrotecnologica, v.29, n.5, p.988-994. 2005.

NAKAGAWA, J.; CAVARIANI, C.; ZUCARELI, C. Maturação formas de secagem e qualidade fisiológica de sementes de mucuna-preta. Revista

Brasileira de Sementes, v.27, n.1, p.45-53, 2005.

PASSOS, M. A.; ALVES, A. R.; TAVARES, K. Germinação de sementes de sabiá (Mimosa caesalpiniifolia, Benth.). Revista Brasileira de Ciência Agrária, v.2, n.1, p.51-56, 2007.

PONTES, C. A. et al. Mobilização de reservas em sementes de Apuleia leiocarpa (Vogel) J.F. Macbr. (garapa) durante a embebição. Revista Árvore, v.26, n.5, p.593-601, 2002.

RIBEIRO JUNIOR, J. I. Análises estatísticas no SAEG. Viçosa, MG: Universidade Federal de Viçosa, 2001. 301p.

ROVERSI, T. et al. Superação da dormência em sementes de acácia negra (Acacia mearnsii Willd.). Revista Brasileira de Agrociência, v.8, n.2, p.161-163, 2002.

SILVA, R. C.; LIMS, E. M.; MAIA, M. R. Temperaturas extremas da cidade de Vitória da Conquista no período de 1997 a 2006: algumas considerações. In: SEMANA DE PESQUISA E PÓS-GRADUAÇÃO DA UESC, 9., 2007, Ilhéus. Anais...Ilheús: UESC, 2007. Disponível em http:// www.seminarioicuesc.com.br/sistema/resumos/ 2007268.pdf. Acesso em: 15 jul. de 2008.

SOUZA, S. M.; LIMA, P. C. F. Maturação de sementes de angico (Anadenanthera macrocarpa (Benth.) Brenan). Revista Brasileira de Sementes, Brasília, v. 7, n. 2, p. 93-99, 1985. 